\title{
Assessment of Need of Antenatal Education by Assessing the Existing Knowledge of Pregnant Women
}

\author{
Basit Ali Khan, Arsh e Mah Muazam, Mubashra Abeeha Shahid
}

\begin{abstract}
OBJECTIVE: To assess the antenatal knowledge and preferred information seeking behavior of pregnant women attending antenatal care clinics of Allied Hospitals of Rawalpindi Medical University, Rawalpindi. METHODOLOY: This was a multi-centered based cross-sectional design study. This study was conducted in the antenatal care clinics of three allied hospitals of Rawalpindi medical University, Rawalpindi. A total of $\mathbf{4 0 0}$ pregnant women in third trimester of pregnancy, attending antenatal care clinics were included in the study through consecutive sampling. Antenatal knowledge was assessed by a valid (scale-content validity index $=1.00$ ) and reliable (Cronbach's alpha $=0.90$ ) questionnaire developed for this purpose. SPSS 22 was used for data analysis.

RESULTS: Out of 400 pregnant women, majority $148(37 \%)$ were in the age group of 23-27 years. Mean age was $26.5 \pm 4.8$ years. Mean antenatal knowledge score was $28 \pm 6.2$. Two hundred and sixty-eight $(67 \%)$ women had poor ( $<70 \%$ score), ninety-six $(24 \%)$ had adequate $(70 \%-80 \%$ score) and thirty-six $(9 \%)$ had good $(>80 \%$ score) level of antenatal knowledge. Three hundred and sixty $(90 \%)$ women had poor nutritional and gestational weight gain knowledge. Antenatal knowledge scores were significantly associated with education, number of antenatal care visits, locality and monthly household income. One to one education was preferred format by most $(53 \%)$ of women. Doctors were the preferred source of information by $80 \%$ of the participants.

CONCLUSION: The findings of the study indicate that most of the pregnant women lack the adequate antenatal knowledge while one to one education given by doctors was the preferred mode of health education by the majority of the participants.
\end{abstract}

KEYWORDS: Pregnant women, Antenatal education, Antenatal knowledge.

This article may be cited as: Khan BA, Muazam AM, Shahid MA. Assessment of Need of Antenatal Education by Assessing the Existing Knowledge of Pregnant Women. J Liaquat Uni Med Health Sci. 2019;18(03):206-13. doi: 10.22442/jlumhs.191830629

\section{INTRODUCTION}

Antenatal care (ANC) means "Care Before Birth", it is the systematic assessment and follow-up of pregnant women, comprising education, counseling, screening, and treatment ${ }^{1,2}$. Antenatal education interventions can change the attitudes and practices of pregnant women to achieve better health for themselves and for their babies $^{2}$. Such interventions provide pregnant women with the necessary information regarding danger signs of pregnancy ${ }^{2-8}$.

Health education is an important element of antenatal care $^{9}$. Several studies have reported that health education given to expectant mothers can reduce complications of pregnancy ${ }^{9}$.

Pakistan has a maternal mortality rate of 178 maternal deaths per 100,000 live births (est. 2015) ${ }^{10}$. A recent UNICEF report (2018) reveals that Pakistan has the highest neonatal mortality rate (45.6 deaths per 1000 live births) in the world ${ }^{11}$. According to Pakistan Demographic Household Survey (PDHS) 2012-2013 only $48 \%$ deliveries in Pakistan take place in health-care facilities while the antenatal-care coverage accounts for $73 \%{ }^{12}$. This gap could be due to the lack of awareness of pregnant women on importance of antenatal care $^{13}$. Many well-established antenatal education programs exist in developed countries and consequently such programs are needed in developing countries as well ${ }^{14}$. At present there is no country-wide comprehensive program for antenatal education in Pakistan. In developed countries many expecting mothers, especially primigravida, attend antenatal education classes, which ensure better health during pregnancy and prepare them for delivery. There is a clear need for such interventions targeting Pakistani women. A study conducted in Bahawalpur, Pakistan (2012) reported that antenatal clients were not receiving information and education communication according to World Health Organization guidelines ${ }^{13}$. According to the literature a very rare or no other published study has comprehensively described the preferred information seeking behavior or the antenatal educational needs among the Pakistani population.

This study has assessed antenatal knowledge of 
expecting mothers attending three tertiary care hospitals of Rawalpindi, Pakistan and has identified health education needs of target population and their preferences regarding format and source of antenatal education. This study was conducted in pregnant women in the third trimester of pregnancy in order to identify the antenatal knowledge gap of the study participants and to assess the quality of present source of antenatal education, which in our case is usually antenatal care clinics and to give recommendations for development of antenatal education program in Pakistan.

\section{METHODOLOGY}

This multi-centered based, cross-sectional study was conducted in the antenatal care clinics of three allied hospitals (Holy Family Hospital, District Head Quarter Hospital and Benazir Bhutto Hospital) of Rawalpindi Medical University between March and July of 2018. These hospitals are tertiary care hospitals and being public in nature, provide treatment to the majority of population. The STROBE (Strengthening the Reporting of Observational studies in Epidemiology) guidelines ${ }^{15}$ were used to report the data. Minimum required sample size as calculated by $\mathrm{WHO}$ calculator was 384 , using anticipated population proportion = 0.10 (anticipated proportion of good antenatal knowledge $)^{2}$, absolute precision $=0.03$ and confidence level $=95 \%$. But we included 400 pregnant women in our study. Pregnant women in the third trimester of pregnancy, attending antenatal care clinics and familiar with Urdu (national language of Pakistan) or English, were included in the study through non-probability consecutive sampling technique.

The Ethical Review Board of the Institutional Research Forum of Rawalpindi Medical University, Rawalpindi approved the study protocol. This project conforms to the provisions of the Declaration of Helsinki ${ }^{16}$. Written consent on a specially designed consent form was taken from the participants prior to the data collection. Participants received a detailed explanation of the study and were assured about the confidentiality of the responses and their right to withdraw from the study at any time.

A 34-item structured questionnaire, comprising 4 sections was used for data collection. Section-1 on sociodemographic details, Section-2 on obstetrics details, Section-3 on antenatal knowledge (comprising 30 questions) and Section-4 comprising questions on present source of information and preferred source and format of antenatal education (4 questions). Section on antenatal knowledge was further divided into 7 domains including nutritional knowledge, gestational weight gain knowledge, exercise knowledge, danger signs knowledge, antenatal clinic knowledge, knowledge about dos and don'ts of pregnancy and birth spacing knowledge. A knowledge scoring key was also developed using WHO recommendations on antenatal care ${ }^{17}$, WHO guidelines for birth spacing ${ }^{18}$, food composition table for Pakistan ${ }^{19}$ and Food and Agriculture Organization (FAO) guidelines for assessing nutrition-related knowledge, attitudes and practices ${ }^{20}$. The primary version of the questionnaire (comprising 40 questions) in English was developed after an extensive literature review and following WHO recommendations on antenatal care ${ }^{17}$. The English version was translated into Urdu by a bilingual professional translator. The translation committee (one translator and three researchers) checked and agreed on an Urdu version of the questionnaire. Face validity of the questionnaire was done by 4 experts (two gynecologists, one biostatistician and one community medicine teacher), number of questions were reduced to 36 in postface-validity version. A panel of content experts (05 gynecologists) judged the content validity of the questionnaire. Post face-validity version was sent to the bilingual expert panel. Content validity was assessed by asking the members to rate each item as a valid measure of construct using a 4-point scale (1= not relevant, 2 somewhat relevant, $3=$ quite relevant, $4=$ highly relevant). A content validity index was calculated for each item and for the overall questionnaire. An acceptable item level content validity index (I-CVI) for 5-member expert panel should be $1.00^{21}$. Two items with I-CVI less than 1.00 were deleted from the questionnaire, decreasing the size of questionnaire to 34-items. Scale level content validity index/ Universal Agreement (S-CVI/UA) of overall 34-item questionnaire was 1.00 . In addition, the panel was also asked to rate each item on the basis of clarity. Minor changes were suggested on the fluency of one item. The post content validity version of the questionnaire was pilot tested with 20 pregnant women meeting the inclusion criteria of the study. This was done to check the data collection procedure, administration of questionnaire for clarity and participants' willingness to complete it. Cronbach's alpha $(\alpha)$, showing internal consistency, for overall questionnaire was found to be 0.900 . Minor modifications were needed after pilot testing the questionnaire with 20 women. Data from the pilot-testing was not included in the final analysis. After establishment of validity and reliability of the study questionnaire, the instrument was made available for data collection. Figure I showing different stages in development of questionnaire. 
FIGURE I:

\begin{tabular}{c}
$\begin{array}{c}\text { Developed a primary version of the questionnaire in English after } \\
\text { literature review }\end{array}$ \\
Translated into Urdu by a bilingual professional translator \\
\hline $\begin{array}{c}\text { Reviewed for face validity by } 4 \text { experts and a post face validity } \\
\text { version was developed }\end{array}$ \\
$\begin{array}{c}\text { Reviewed by a 5-experts panel for content validity and a post } \\
\text { content validity version was developed }\end{array}$ \\
Pilot tested (N=20) the panel modified version and developed a \\
pilot tested version \\
Valid and reliable questionnaire used for data collection.
\end{tabular}

SPSS version 22 was used for the statistical analysis. Descriptive statistics were used to elaborate participants' demographic characteristics, obstetrics details and knowledge scores. A cumulative knowledge score was computed for all the study articipants based on their responses. The knowledge scores were converted to percentages, and the study participants were categorized as having a good level (above $80 \%$ ), an adequate level $(70-80 \%$ ), or a poor level (below $70 \%$ ) of knowledge. Chi-square test was used to find association between categorical variables. For numeric variables, normality was assessed by histograms with fitted normal curve, $Q-Q$ plots and Kolmogorov Smirnov test, and the data was found to be normally distributed. So, for numeric variables independent t-test and one-way ANOVA test were used to establish association. A p-value of $<0.05$ was considered to be statistically significant.

\section{RESULTS}

The socio-demographic and pregnancy characteristics of the participants are presented in Table I. Out of 400 participants, majority $148(37 \%)$ were in the age group of 23-27 years. Mean age of the study population was $26.5 \pm 4.8$ years.

Nutritional knowledge of the pregnant women was assessed by asking 13 pre-categorized questions on nutrition. A score of 1 was given to any correct response from a list of correct answers; 0 score was given to wrong response; and 0.5 score was given to "other responses" (not listed in the questionnaire), but considered correct by the analyst. Nutritional knowledge score ranged from 0 (minimum) to 13 (maximum). Mean nutritional knowledge score was 4.8 \pm 2.9 Table II.

One hundred and sixty-four (41\%) had knowledge about health risks associated with lack of iron in the diet.One hundred and ninety-six (49\%) had knowledge about supplements taken in pregnancy. One hundred and seventy-six (44\%) knew the sources of iron; $112(28 \%)$ had knowledge about sources of calcium; while only $84(21 \%)$ had knowledge about source of iodine. Mean nutritional knowledge scores were significantly associated with education $(p<0.001)$, monthly household income $(p<0.001)$, age $(p=0.039)$, number of pregnancies $(p=0.013)$, the number of children $(p=0.005)$ and the number of antenatal care visits $(p=0.001)$.

Gestational weight gain knowledge was assessed by asking 4 pre-categorized questions. Gestational weight gain knowledge score ranged from 0 (minimum) to 4 (maximum). Mean gestational weight gain knowledge score was 1.2 \pm 1.0 Table II.

Only $32(8 \%)$ women correctly indicated the recommended gestational weight gain. Two hundred and sixteen (54\%) had knowledge about the measures to be taken to avoid excessive weight gain during pregnancy. Two hundred and sixty (65\%) women thought excessive weight of mother leads to complications for mother during pregnancy. Only 156 (39\%) participants thought that excessive weight gain of mother can lead to complications in baby. Mean gestational weight gain knowledge scores were found to be significantly associated with number of antenatal care visits $(p=0.001)$ and employment status $(p=0.025)$.

TABLE I: SOCIODEMOGRAPHIC DETAILS $(n=400)$

\begin{tabular}{|c|c|c|}
\hline Characteristics & Frequency $(n)$ & $\%$ \\
\hline \multicolumn{3}{|l|}{ Age $(26.5 \pm 4.9$ years) } \\
\hline $18-22$ years & 96 & 24 \\
\hline 23-27 years & 148 & 37 \\
\hline 28-32 years & 104 & 26 \\
\hline 33-37 years & 44 & 11 \\
\hline$\geq 38$ years & 08 & 2 \\
\hline \multicolumn{3}{|l|}{ Education } \\
\hline None & 88 & 22 \\
\hline Primary & 24 & 6 \\
\hline Middle & 36 & 9 \\
\hline Secondary & 92 & 23 \\
\hline Higher Secondary & 60 & 15 \\
\hline University & 100 & 25 \\
\hline \multicolumn{3}{|l|}{ Employment Status } \\
\hline Employed & 80 & 2 \\
\hline Unemployed & 392 & 98 \\
\hline \multicolumn{3}{|l|}{ Locality } \\
\hline Urban & 328 & 82 \\
\hline Rural & 72 & 18 \\
\hline
\end{tabular}




\begin{tabular}{|c|c|c|}
\hline \multicolumn{3}{|c|}{ Monthly Household Income † } \\
\hline$\leq$ Rs. 10,000 & 80 & 20 \\
\hline Rs. $11,000-20,000$ & 128 & 32 \\
\hline Rs. $21,000-30,000$ & 52 & 13 \\
\hline Rs. $31,000-40,000$ & 56 & 14 \\
\hline$\geq$ Rs. 41,000 & 84 & 21 \\
\hline \multicolumn{3}{|l|}{ Gravidity $(2.7 \pm 1.7)$} \\
\hline One & 120 & 30 \\
\hline 2 to 4 & 232 & 58 \\
\hline$\geq 5$ & 48 & 12 \\
\hline \multicolumn{3}{|c|}{ Number of children $(1.4 \pm 1.3)$} \\
\hline 0 (none) & 132 & 33 \\
\hline 1 to 3 & 248 & 62 \\
\hline$\geq 4$ & 20 & 5 \\
\hline \multicolumn{3}{|c|}{ Number of antenatal care visits $(5.3 \pm 2.3)$} \\
\hline$<5$ & 169 & 42 \\
\hline$\geq 5$ & 232 & 58 \\
\hline \multicolumn{3}{|c|}{ † 1 PKR. $=0.0086$ USD } \\
\hline
\end{tabular}

TABLE-II: KNOWLEDGE LEVEL OF STUDY PARTICIPANTS IN DIFFERENT DOMAINS $(n=400)$

\begin{tabular}{|l|r|r|r|}
\hline \multirow{2}{*}{\multicolumn{1}{|c|}{ Domains }} & \multicolumn{3}{|c|}{ Knowledge level $\mathbf{n}(\%)$} \\
\cline { 2 - 4 } & \multicolumn{1}{c|}{ Poor } & Adequate & \multicolumn{1}{c|}{ Good } \\
\hline Nutritional knowledge & $360(90)$ & $24(6)$ & $16(4)$ \\
\hline $\begin{array}{l}\text { Gestational weight gain } \\
\text { knowledge }\end{array}$ & $360(90)$ & $28(7)$ & $12(3)$ \\
\hline Exercise knowledge & $116(29)$ & $20(5)$ & $264(66)$ \\
\hline Danger signs knowledge & $64(16)$ & $24(6)$ & $312(78)$ \\
\hline $\begin{array}{l}\text { Antenatal clinic } \\
\text { knowledge }\end{array}$ & $76(19)$ & $248(62)$ & $76(19)$ \\
\hline $\begin{array}{l}\text { Knowledge about dos } \\
\text { and don'ts of pregnancy }\end{array}$ & $276(69)$ & $108(27)$ & $16(4)$ \\
\hline Birth spacing knowledge & $172(43)$ & - & $228(57)$ \\
\hline
\end{tabular}

Exercise knowledge was assessed by asking two pre-categorized questions. Two hundred and sixty-four (66\%) women had good exercise knowledge Table II. Out of 400, three hundred and forty-four $(86 \%)$ thought that exercise is helpful during pregnancy. Mean exercise knowledge scores were significantly associated with education $(p<0.001)$, number of pregnancies $(p=0.001)$, number of children $(p=0.005)$, monthly household income $(p=0.001)$ and locality $(p<0.001)$.

Knowledge about Danger signs of pregnancy was assessed by asking 11 'yes' or 'no' questions. Danger signs knowledge score ranged from 0 (minimum) to 11 (maximum). Mean danger signs knowledge score was 9.6 \pm 2.6 Table II. Most recognized danger signs were high blood pressure 392 (98\%), absence of fetal movements $388(97 \%)$, and vaginal bleeding 380 (95\%). Least recognized danger signs were blurred vision 272 (68\%) and severe headache 268 (67\%).

Antenatal clinic knowledge was assessed by asking 10 questions. Antenatal clinic knowledge score ranged from 0 (minimum) to 10 (maximum). Mean antenatal clinic knowledge score was $7.5 \pm 1.2$ Table II. Two hundred and ninety-six (74\%) correctly reported the recommended number of antenatal care visits $(\geq 8$ as recommended by $\mathrm{WHO})^{17}$ during pregnancy. Only $84(21 \%)$ women had knowledge about tetanus vaccination during pregnancy. Mean antenatal clinic knowledge scores were significantly associated with education $(p<0.001)$, monthly household income $(p<0.001)$, age $(p=0.003)$ and number of antenatal care visits $(p<0.001)$.

Knowledge about do's and don'ts of pregnancy was assessed by asking 2 pre-categorized questions. Most women 276 (69\%) had poor knowledge about dos and don'ts of pregnancy Table II.

Knowledge about birth spacing was assessed by asking 3 questions on birth spacingTable II. Three hundred and twenty (80\%) thought that birth spacing is a good practice. Three hundred and seventy-six $(94 \%)$ correctly reported the recommended spacing after a live birth before attempting the next pregnancy $(\geq 2 \text { years as recommended by } \mathrm{WHO})^{18}$. Only 263 $(59 \%)$ knew the methods of birth spacing. Mean birth spacing knowledge scores were significantly associated with locality $(p=0.021)$, education $(p=0.001)$, monthly household income $(p=0.001)$, the number of antenatal care clinic visits $(p=0.047)$, number of pregnancies $(p<0.001)$, and the number of children $(p=0.001)$.

The overall antenatal knowledge score was calculated by adding up the scores of all the 7 domains. Antenatal knowledge score ranged from 0 (minimum) to 45 (maximum). Mean antenatal knowledge score was $28 \pm 6.2$ Figure II. Mean antenatal knowledge scores were significantly associated with education level, number of antenatal care visits, locality and monthly household income Table III. A Turkey post hoc test revealed that the mean antenatal knowledge scores were significantly higher in women with secondary $(29.7 \pm 5.8, \quad p<0.001)$, higher secondary $(28.0 \pm 6.0, p<0.001)$ and university level $(31.5 \pm 3.4$, $\mathrm{p}<0.001$ ) education compared to the women with no formal education $(24.2 \pm 6.6)$. Similarly, women with monthly household income of Rs. $31,000-40,000$ 
Basit Ali Khan, Arsh e Mah Muazam, Mubashra Abeeha Shahid

$(29.8 \pm 4.7, p<0.001)$ and with equal to or greater than Rs. $41,000(31.6 \pm 3.5, p<0.001)$ had significantly higher mean antenatal knowledge scores than women with monthly household income of equal to or less than Rs. $10,000(25.6 \pm 9.0)$.

Table IV presents preferred information seeking behavior of study participants. Out of 400 participants, two hundred and fifty-six (64\%) mentioned doctors as their present source of information. Present source of information was found to be significantly associated with age group $(p<0.001)$.

TABLE III: ASSOCIATION OF DEMOGRAPHIC CHARACTERISTICS AND MEAN ANTENATAL KNOWLEDGE SCORE $(n=400)$

\begin{tabular}{|c|c|c|c|}
\hline Characteristics & $\mathbf{N}$ & $\begin{array}{l}\text { Antenatal Knowl- } \\
\text { edge Score } \\
\text { [mean (SD)] }\end{array}$ & $\begin{array}{c}\text { P- } \\
\text { Value* }^{*}\end{array}$ \\
\hline \multicolumn{4}{|c|}{ Age $(26.5 \pm 4.9$ years $) \dagger$} \\
\hline $18-22$ years & 96 & 26.92(8.2) & 0.796 \\
\hline 23-27 years & 148 & $28.08(5.3)$ & \\
\hline 28-32 years & 104 & $28.05(4.5)$ & \\
\hline 33-37 years & 44 & $29.79(7.9)$ & \\
\hline$\geq 38$ years & 8 & $29.00(4.2)$ & \\
\hline \multicolumn{3}{|l|}{ Education $\dagger$} & $<0.001$ \\
\hline None & 88 & $24.17(6.7)$ & \\
\hline Primary & 24 & 24.62(4.6) & \\
\hline Middle & 36 & $25.44(6.3)$ & \\
\hline Secondary & 92 & $29.71(5.9)$ & \\
\hline Higher Secondary & 60 & $28.02(6.2)$ & \\
\hline University & 100 & $31.53(3.4)$ & \\
\hline \multicolumn{4}{|l|}{ Employment Status $\ddagger$} \\
\hline Employed & 8 & $31.13(0.9)$ & 0.474 \\
\hline Unemployed & 392 & $27.94(6.2)$ & \\
\hline \multicolumn{4}{|l|}{ Locality $\ddagger$} \\
\hline Urban & 328 & $28.63(5.6)$ & 0.031 \\
\hline Rural & 72 & $25.17(8.0)$ & \\
\hline \multicolumn{3}{|c|}{ Monthly Household Income † } & 0.008 \\
\hline$\leq$ Rs. 10,000 & 80 & $25.65(9.2)$ & \\
\hline Rs. $11,000-20,000$ & 128 & $26.39(5.4)$ & \\
\hline Rs. $21,000-30,000$ & 52 & $27.88(4.4)$ & \\
\hline Rs. $31,000-40,000$ & 56 & $29.77(4.8)$ & \\
\hline$\geq$ Rs. 41,000 & 84 & $31.60(5.6)$ & \\
\hline \multicolumn{4}{|l|}{ Gravidity $(2.7 \pm 1.7) \dagger$} \\
\hline One & 120 & $28.40(5.4)$ & 0.400 \\
\hline
\end{tabular}

\begin{tabular}{|c|c|c|c|}
\hline 2 to 4 & 232 & $28.26(6.7)$ & \\
\hline$\geq 5$ & 48 & $25.73(5.2)$ & \\
\hline \multicolumn{4}{|c|}{ Number of children $(1.4 \pm 1.3) \dagger$} \\
\hline 0 (none) & 132 & 28.39(5.7) & 0.403 \\
\hline 1 to 3 & 248 & $28.08(6.6)$ & \\
\hline$\geq 4$ & 20 & $24.40(4.2)$ & \\
\hline \multicolumn{4}{|c|}{ Number of antenatal care visits $(5.3 \pm 2.3) \ddagger$} \\
\hline$<5$ & 168 & $26.30(6.6)$ & 0.018 \\
\hline$\geq 5$ & 232 & $29.24(5.6)$ & \\
\hline
\end{tabular}

TABLE IV: PREFERRED INFORMATION SEEKING BEHAVIOR OF STUDY RESPONDENTS $(n=400)$

\begin{tabular}{|c|c|c|}
\hline Present Source $†$ & Frequency (n) & \%age \\
\hline Doctors & 256 & 64 \\
\hline Nurses & 16 & 4 \\
\hline Family and friends & 208 & 52 \\
\hline Mass media & 60 & 15 \\
\hline Other & 20 & 5 \\
\hline \multicolumn{3}{|c|}{ Interested in Getting Antenatal Education } \\
\hline Yes & 384 & 96 \\
\hline No & 16 & 4 \\
\hline \multicolumn{3}{|c|}{ Preferred Format for Antenatal Education $\dagger$} \\
\hline Written material & 88 & 22 \\
\hline Group education & 20 & 5 \\
\hline One to one & 212 & 53 \\
\hline Demonstrations & 24 & 6 \\
\hline Lectures & 92 & 23 \\
\hline Other & 08 & 2 \\
\hline \multicolumn{3}{|c|}{ Preferred Source for Antenatal Education $†$} \\
\hline Doctors & 320 & 80 \\
\hline Health educator & 64 & 16 \\
\hline Nurses & 40 & 10 \\
\hline $\begin{array}{l}\text { Mass media (newspaper, } \\
\text { magazines, TV, radio, } \\
\text { internet) }\end{array}$ & 68 & 17 \\
\hline Other & 44 & 11 \\
\hline \multicolumn{3}{|c|}{ †Multiple responses were observed } \\
\hline
\end{tabular}




\section{FIGURE II: DISTRIBUTION OF ANTENATAL KNOWLEDGE SCORES AMONG STUDY'S PARTICIPANTS}

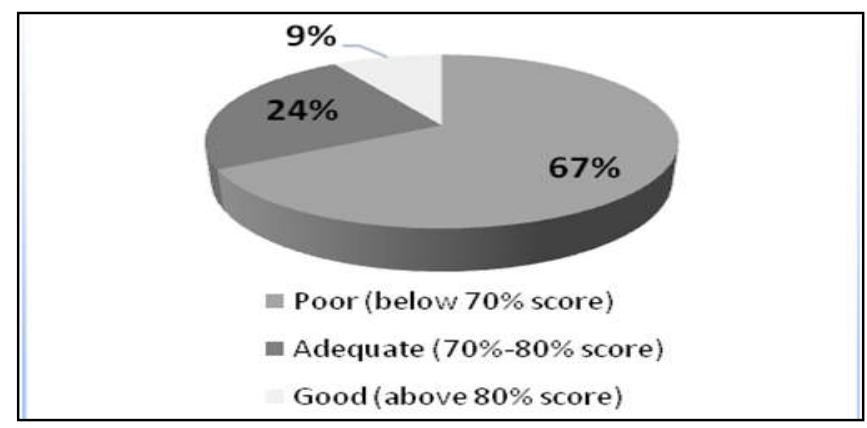

\section{DISCUSSION}

Well-developed antenatal education programs greatly influence the effectiveness of antenatal education interventions in any country ${ }^{2,22}$. Identifying the weaker areas of antenatal knowledge, and preferred format and source for antenatal education among this population may impact the quality and outcome of antenatal education programs in Pakistan. Most of the pregnant women $(67 \%)$ assessed in this study had poor antenatal knowledge. A study conducted in Saudi Arabia has reported the similar findings ${ }^{2}$. The results confirm a notable lack of antenatal knowledge of expecting mothers. The antenatal knowledge of the pregnant women was assessed in seven domains using a specially designed questionnaire; each domain is discussed briefly below:

Most of the pregnant women had poor nutritional knowledge. Level of Knowledge about food that is a rich source of iron was also found to be low. This lack of awareness regarding dietary source of iron could be the cause of high prevalence $(76.7 \%)$ of iron deficiency anemia among Pakistani pregnant women reported in a recent study ${ }^{23}$. Contrary to the studies conducted in Australia ${ }^{24,25}$, a small percentage of women were aware of folic acid (28\%) and iron (27\%) supplementation. Misconceptions in a range of areas were also observed (like mentioning milk as a source of iron and citrus fruits as source of calcium). In consistent with other studies ${ }^{25,26}$, nutritional knowledge was found to be significantly associated with monthly household income, education and number of antenatal care visits. Nutrition education programs directed towards high risk-groups are needed to be established in Pakistan.

The results of the study confirm a notable lack of gestational weight gain knowledge of pregnant women. Only 04 out of 400 women mentioned diabetes as the complication during pregnancy due to excessive weight gain of the mother. Various misconceptions were also noticed. Findings suggest that, special attention to the awareness about gestational weight gain is needed.

Most of the women thought that exercise is helpful during pregnancy; but they didn't know that exercises like swimming and stationary cycling even existed for pregnant mothers. Lack of knowledge about prenatal exercises can be due to social and cultural barriers and lack of prenatal exercise classes in Pakistan factors which are needed to be explored in future researches. This clearly shows the need for educating the society about prenatal exercises.

Most of the study participants were well aware of the danger signs of pregnancy; but only a small number of women recognized blurred vision and severe headache as danger signs of pregnancy. Findings of the study suggest that maternal health care professionals should emphasize these danger signs when providing antenatal education to the expecting mothers.

Most of the women had poor knowledge about dos and don'ts of pregnancy. Most women were unaware regarding dietary precautions, monitoring baby's movements, taking prescribed supplements and avoiding smoking, caffeine and unprescribed drugs during pregnancy.

Antenatal education should be completed with provision of information regarding birth spacing. Only a few participants were aware of birth control methods. Lack of birth spacing knowledge can be due to many social, cultural and religious factors. Birth spacing knowledge was significantly associated with number of pregnancies and children; with multigravida having better birth spacing knowledge than primigravida.

Overall antenatal knowledge was significantly associated with the level of education. This could be explained by the fact that expecting mothers with higher education may have less difficulty in understanding the information received during antenatal care visits ${ }^{28}$. Monthly household income had a positive effect on increasing women's antenatal knowledge. This may due the fact that women with lower socioeconomic status have difficulty in seeking medical advice ${ }^{29}$.

Most of the questioned women (53\%) preferred to get antenatal education through one to one education. Most of them preferred to get one to one education by a doctor. A few mothers stated that they preferred to be educated by health educators - a finding consistent with a study from Saudi Arabia ${ }^{2}$. People need to be aware of role and importance of each health care specialist. Group education is the most effective way of producing long term changes in behaviors of parents ${ }^{30}$. Surprisingly, a small percentage $(5 \%)$ of women preferred group education. Similarly, a few women were interested in getting education through mass media - a cost effective 
method of providing information to the community. The findings of this study related to preferences for format and source are may be due to cultural differences, low literacy rate, lack of access to internet facilities and print media. Further researches are needed to explore such factors.

There were certain limitations to this study. Women who participated in this study were recruited through non-probability consecutive sampling and were restricted to those who attended antenatal care clinics of allied hospitals of Rawalpindi medical university, Rawalpindi. Thus, the results are difficult to generalize to all pregnant women residing in Pakistan. Since, the design of this study is cross-sectional, no causal interpretations can be made of relationships between variables.

Antenatal education programs, emphasizing weaker areas of knowledge and designed according to preferred format and source, need to be developed for the population. Special educational programs directed towards women in less-educated and lower-income groups; those living in rural areas and not attending/ less-frequently attending antenatal clinics should also be developed.

\section{CONCLUSION}

There is a clear need for antenatal education in this population as shown by low knowledge scores. Extensive antenatal education campaigns and programs should be developed for pregnant women in hospitals as well as in community settings. This study has revealed an understanding regarding preferred format and sources of antenatal education. The findings of this study are a proposal and recommendations for the planning and development of properly structured antenatal education programs suitable for the Pakistani population.

\section{ACKNOWLEDGMENTS}

We would like to thank our supervisor, Dr. Farhan Hassan, for useful advice and comments during the whole process of the study. We would also like to thank Dr. Sanjeeda Begum, Dr. Khadija Khatoon, Dr. Naushin Farooq, Dr. Asma Ehsan and Dr. Sadat, who contributed in the content validity of the study questionnaire. We also acknowledge the respondents for participating in the study.

Ethical permission: Rawalpindi Medical University ERC approval dated 27-04-2018.

Conflict of interest: Authors of the study have no conflict of interest to declare.

Funding: None to declare

\section{REFERENCES}

1. Liu X, Behrman JR, Stein AD, Adair LS, Bhargava SK, Borja JB, et al. Prenatal care and child growth and schooling in four low- and medium-income countries. PLoS One. 2017; 12(2): e0171299. doi:10.1371/journal.pone.0171299.

2. Otaiby TA, Jradi $H$, Bawazir A. Antenatal Education: An Assessment of Pregnant Women Knowledge and Preferences in Saudi Arabia. $J$ Women's Health Care. 2013;2:4. doi: 10.4172/2167-0420.1000139.

3. Beeckman K, Louckx F, Putman K. Determinants of the number of antenatal visits in a metropolitan region. BMC Public Health. 2010; 10: 527. doi:10.1186/1471-2458-10-527.

4. United States Agency for International Development (USAID), author Focused antenatal care: Providing integrated, individualized care during pregnancy. USAID; 2007.

5. Sword W, Heaman M, Biro MA, Homer C, Yelland J, Danesh NA, et al. Quality of prenatal care questionnaire: psychometric testing in an Australia population. BMC Pregnancy and Childbirth. 2015; 15: 214. doi:10.1186/s12884-015-0644-7.

6. Brixval CS, Thygesen LC, Axelsen SF, Gluud C, Winkel $P$, Lindschou J, et al. Effect of antenatal education in small classes versus standard auditorium-based lectures on use of pain relief during labour and of obstetric interventions: results from the randomised NEWBORN trial BMJ Open 2016;6:e010761. doi: 10.1136/bmjopen2015-010761.

7. Mbuagbaw L, Medley N, Darzi AJ, Richardson M, Habiba Garga K, Ongolo-Zogo P. Health system and community level interventions for improving antenatal care coverage and health outcomes. Cochrane Database Syst Rev. 2015; 12: 1 -157. doi:10.1002/14651858.CD010994.pub2.

8. Shi $Y$, Wang $D$, Yuan $Y$, Jiang $Y$, Zeng $Q$, Chang C. The effect of prenatal education curriculum on mother's prenatal examination utilization, delivery mode and recovery status: a cross-sectional survey in China. Environ Health Prev Med. 2015; 20(6): 397-403. doi:10.1007/s12199-015-0480-4.

9. Al-Ateeq MA, Al-Rusaiess AA. Health education during antenatal care: the need for more. Int $\mathrm{J}$ Women's Health. 2015; 7: 239-42. doi: 10.2147/ IJWH.S75164.

10. Central Intelligence Agency [internet].The world factbook: Country comparison: Maternal mortality rate; [cited 2018 Aug 08]. Available from: https:// www.cia.gov/library/publications/the-worldfactbook/rankorder/2223rank.html

11. UNICEF. Every child alive - The urgent need to end newborn deaths. 2018. Available from: https:// 
www.unicef.org/publications/index_102640.html

12. National Institute of Population Studies (Pakistan), MEASURE DHS ICF International USA. Pakistan Demographic and Health Survey 2012-13. December 2013. Available from: https:// www.nips.org.pk/abstract_files/PDHS\%20Final\% 20Report\%20as\%20of\% 20 Jan\%2022-2014.pdf

13. Mahar B, Kumar R, Rizvi N, Bahalkani HA, Haq $M$, Soomro J. Quantity and quality of information, education and communication during antenatal visit at private and public sector hospitals of Bahawalpur, Pakistan. J Ayub Med Coll Abbottabad. 2012; 24(3-4): 71-4.

14. Akhund S, Avan BI. Development and pretesting of an information, education and communication (IEC) focused antenatal care handbook in Pakistan. BMC Research Notes. 2010. doi:10.1186/1756-0500-4-91

15. Vandenbroucke JP, von Elm E, Altman DG, Gotzsche PC, Mulrow CD, Pocock SJ, et al. Strengthening the Reporting of Observational Studies in Epidemiology (STROBE): explanation and elaboration. PLoS Med. 2007 Oct 16; 4(10): e297.

16. World Medical Association. World Medical Association Declaration of Helsinki: ethical principles for medical research involving human subjects. JAMA. 2013; 310(20): 2191-4. doi: 10.1001/jama.2013.281053.

17. WHO. WHO recommendations on antenatal care for a positive pregnancy experience. 2016. Available from: https://www.who.int/ reproductivehealth/publications/maternal_perinatal_health/anc-positive-pregnancy-experience/en/

18. WHO. Report of a WHO Technical Consultation on Birth Spacing. 2005. Available from: https:// www.who.int/maternal_child_adolescent/ documents/birth_spacing05/en/

19. Dept. of Agri Chem NWFP Agri University Peshawar, UNICEF (Islamabad), P\&D Govt. of Pakistan. Food composition table for Pakistan (Revised 2001). UNICEF. 2001. Available from: https://www.aiou.edu.pk/FoodSite/ FCTView OnLine. html

20. Macias YF, Glasauer P. Guidelines for assessing nutrition-related Knowledge, Attitudes and Practice. Food Agri Org United Nations. 2014. Available from: http://www.fao.org /3/i3545e/ i3545e00.htm

21. Polit DF, Beck CT. The content validity index: Are you sure you know what's being reported? Critique and recommendations. Res Nurs Health. 2006; 29(5): 489-97

22. Collins $\mathrm{C}$. The discrepancy between the information pregnant women expect and receive in Ireland and the lost opportunity for health promotion and education. Int $\mathrm{J}$ Health Prom Edu. 2007; 45(2): 61-66. doi:10.1080/14635240.2007. 10708102.

23. Shams S, Ahmad Z, Wadood A. Prevalence of Iron Deficiency Anemia in Pregnant Women of District Mardan, Pakistan. J Preg Child Health. 2017; 4(6): 356 . doi: 10.4172/2376-127X. 1000356 .

24. El-mani S, Charlton KE, Flood VM, Mullan J. Limited knowledge about folic acid and iodine nutrition in pregnant women reflected in supplementation practices. Nutr Diet. 2014;71 (4):236-244.

25. Bookari K, Yeatman H,Williamson M. Exploring Australian women's level of nutrition knowledge during pregnancy: a cross-sectional study. Int J Women's Health. 2016; 8: 405-419. doi:10.2147/ IJWH.S110072.

26. McLeod ER, Campbell KJ, Hesketh KD. Nutrition knowledge: a mediator between socioeconomic position and diet quality in Australian first-time mothers. J Am Diet Assoc. 2011; 111(5): 696-704. doi: 10.1016/j.jada.2011.02.011.

27. Bookari K, Yeatman H, Williamson M. Australian Pregnant Women's awareness of gestational weight gain and dietary guidelines: opportunity for action. J Pregnancy. 2016; ID 8162645: 1-9. doi: 10.1155/2016/8162645.8162645.

28. Duysburgh E, Ye M, Williams A, Massawe S, Sié A, Williams J,et al. Counselling on and women's awareness of pregnancy danger signs in selected rural health facilities in Burkina Faso, Ghana and Tanzania. Trop Med Int Health.2013; 18(12): 1498-509. doi:10.1111/tmi.12214.

29. Doctor HV, Findley SE, Cometto G, Afenyadu GY. Awareness of critical danger signs of pregnancy and delivery, preparations for delivery, and utilization of skilled birth attendants in Nigeria. J Health Care Poor Underserved. 2013;24(1):152 -70 doi: $10.1353 / \mathrm{hpu} .2013 .0032$.

30. Wellington L, White KM, Liossis P. Beliefs underlying intentions to participate in group parenting education. Australian e-journal for the Advancement of Mental Health. 2006; 5(3): 275-83.
AUTHOR AFFILIATION:
Email: ali19145@yahoo.com
Dr. Arsh e Mah Muazam
Dr. Mubashra Abeeha Shahid
Rawalpindi Medical University
Rawalpindi-Pakistan.

Dr. Basit Ali Khan (Corresponding Author) 